\title{
"Si marzo tuerce el rabo, ni pastores ni ganados": ecología, superstición, cuento popular, mito pagano y culto católico del mes de marzo
}

"Repetición" y "regeneración" son dos de los términos que Mircea Eliade asoció a la esencia y la evolución de los mitos. "Ritualización" y "conmemoración" son otros dos términos que, aunque comparten algún asiento semántico sobre los dos primeros, tienen usos netamente diferenciados: "ritualización" se ha especializado en la acepción de eco o supervivencia evolucionada de hechos míticos o credenciales; "conmemoración", en la de sucesos históricos. Entre ambos hay una especie de tierra insuficientemente conocida donde la introducción de cualquier rayo de luz puede hacer avanzar grandemente el conocimiento del período crucial de tránsito del mito a la historia en que están cifradas algunas de las claves más profundas de nuestra cultura.

Pocos campos pueden ser más receptivos a esa luz y ofrecer materia más concreta para la prospección dual, mítográfica e histórica, que el calendario tradicional. Por constituir un entramado ideologizador y organizador básico y estable de la sociedad, una especie de osamenta y nervio de los ciclos de vida y evolución cultural del pueblo, en el calendario de efemérides han quedado reflejadas las improntas de lo mítico y de lo histórico, de lo ritualizado y lo conmemorado, con la nitidez de estratos arqueológicos abiertos al análisis y la deducción. "El estudio del calendario de un pueblo tiene gran interés para el historiador de las religiones y el etnólogo. Con él se aclaran muchas cuestiones relacionadas con las festividades propias de él, su carácter, periodicidad, etc. ${ }^{1}$. Esta afirmación de quien mejor ha estudiado el calendario festivo peninsular, Julio Caro Baroja, resulta - como buena hija de quien abrió tantos caminos y horizontes - verdadera pero modesta, y admite dos añadidos: el de que también desde la filología y la literatura comparada, el estudio del calendario de efemérides de un pueblo - y de lo que tiene de mito ritualizado y de historia conmemorada - puede resultar aleccionador; y el de que, además de rasgos de carácter interno, tal estudio puede ayudarnos a recuperar el

1 Julio CARO BAROJA, Sobre la religión antigua y el calendario del pueblo vasco (San Sebastián: Txertoa, 1984), p. 73. 
marco externo y pluricultural que permita avanzar hacia el entendimiento global de la identidad de ese pueblo.

Una vez establecidas estas coordenadas de interdisciplinariedad y la metodología de contraste de lo particular y esencial de un pueblo con lo general y común a otros pueblos que vamos a utilizar, podemos asomarnos ya al estrato de nuestro campo de estudio donde lo histórico y "lo conmemorativo" se hacen más presentes. A partir de ahí, iremos remontándonos hacia épocas pasadas para intentar recuperar otros estratos superpuestos en que domina lo simplemente "ritualizado": lo mítico, lo supersticioso y, al final -o más bien al principio-, lo puramente cíclicoecológico como condicionante primario de la vida social y espiritual, de la relación con el entorno y las creencias más arraigadas del hombre.

1. La fiesta de la Virgen de la Pellejera (25 de marzo) EN IN PUEBLO IDE VALLADOLID

Un hombre natural de Montemayor de Pililla (Valladolid) me informó en 1993 de que en su pueblo hay una ermita dedicada a Nuestra Señora de la Pellejera, cuya fiesta se celebra todos los años el día 25 de marzo. Al pedirle más detalles sobre el curioso nombre de aquella Virgen y de su culto, me explicó que con su ermita y su fiesta se conmemora un suceso que acaeció en Montemayor hace mucho tiempo. Muchas veces escuchó contar, efectivamente, la historia de un pastor del lugar que prometió un cordero a la Virgen a cambio de que no permitiese que el invierno diezmase su rebano y éste llegase sano y salvo a la primavera. Pero apenas asomó el buen tiempo, creyéndose ya seguro, el pastor renegó de su promesa y no llevó a la Virgen el cordero prometido. Entonces cayó tal helada que murió de frío todo su rebaño, y sólo sobrevivió un cordero que el pastor había refugiado debajo del caldero que pendía sobre el hogar. A pesar de ello, el cordero también perdió el rabo, que había quedado fuera de la protección del caldero y se heló?.

El culto de Nuestra Señora de la Pellejera que se celebra en Montemayor cada 25 de marzo, desde hace siglos y con todas las bendiciones de la Iglesia, es un caso, evidente y trasparente como pocos, de institucionalización histórico-religiosa y "conmemoración" anual de un suceso que los lugareños sitúan en unas coordenadas de tiempo y espacio para ellos absolutamente reales: el pasado y el solar del propio pueblo

\footnotetext{
2 El informante Buenaventura Molpeceres, de 66 años, nacido en Montemayor de Pililla, fue entrevistado en Madrid el 29 de junio de 1993.
} 
"fueron" el escenario de la anécdota del pastor y la Virgen que es tenida por los nativos no sólo como auténtica, sino incluso como pieza clave e indispensable para entender la "historia" y las señas de identidad comunitarias de este pueblo agropastoril.

En el siguiente estrato de análisis daremos el primer paso de lo particular a lo general y podremos situar el culto a la Virgen de la Pellejera en un contexto más global y clarificador. Porque lo que en Montemayor funcionaba como "conmemoración" de un suceso supuestamente "histórico" se va a revelar, en el País Vasco y en Navarra, como complejo cultural híbrido en el que un rito católico de tipo similar al castellano apenas muestra elementos "histórico-conmemorativos" y aparece, en cambio, fuertemente impregnado de ritualizados elementos de carácter mítico-folclórico y -en un estadio todavía más elemental-, de pura, simple y atávica superstición ganadera.

\section{LA FIESTA DE ANDRAMARI MARTXOKO O AMABIRINA MARTXOK() 'NUEST'RA SEÑORA DE MARZO' (25 DE MARZO) FN Fl ÁREA VASCO-NAVARRA}

Efectivamente, en el País Vasco y en Navarra están arraigadas determinadas creencias y cultos en torno a Andramari Martxoko o Amabirjina Martxoko 'Nuestra Señora de Marzo', que el pueblo suele celebrar cada 25 de marzo ${ }^{3}$, el mismo día del culto a la Virgen de la Pellejera en el pueblo vallisoletano. Juan Garmendia Larranaga ha escrito estos reveladores párrafos al respecto:

Aunque oficialmente ha llegado a su fin [el 21 de marzo], prolongaremos el invierno por unos dias. En Aizarnazabal [Guipúzcoa], al igual que en algunas otras localidades, se celebraba el día de Amabirjina Martxoko o día de la Virgen de Marzo. El día 25 de marzo, día del Martxoko Amabirjina, era costumbre en esta localidad invitar a todo el que acudía a vísperas a la parroquia. A los hombres se les ofrecía pan y vino en botellas de dos litros y medio que se servía en vasos y otros recipientes. A las mujeres se les invitaba a un tazón de chocolate con bolados o azucarillos en forma de plátano, en el bar Etxeberri. Del servicios se ocupaban los mayordomos, tres o cuatro baserritarras nombrados por el pueblo. Esta celebración de ambiente festivo desapareció tras la guerra civil, el año 1940 [...] Fl relato al que nos referiremos a continuación es más conocido por zozomikoteak que por artzaitxoaren eguren. Los zozomikote son días tristes y oscuros. En las localidades

3 Del arraigo de esta fiesta da fe el hecho de que Resurrección María DE AZKUE, en Euskalerriaren Yakintza: literatura popular del País Vasco, 4 vols., (reed. Madrid: Euskaltzaindia-Espasa Calpe, 1989), I, p. 317, señalase que 'En toda Nabarra se rezan cien avemarías el día de Nuestra Señora de Marzo; algunos también en Baja Naharra'. 
guipuzcoanas, los días denominados zozomikoteak o artzaitxoaren egunek se refieren a los dos o tres últimos días de marzo y los dos o tres primeros días de abril, sobre todo, en lo que se refiere a nuestra provincia. Una vez un pastor le prometió a Marzo que le obsequiaría con su mejor oveja a cambio de que hiciera buen tiempo. Así, Marzo se puso a su disposición; pero cuando llegaron los dos últimos días del mes, el pastor, en son de burla, le dijo a Marzo que olvidase la promesa: "Ai Martxo, Martxo!, ematen diat esker gaixto. Nere artaldean den ardirik eskaxenak egiten dik errekari bi oinetan salto [' 'Ay, Marzo, Marzo! No te agradezco lo que te debo. En mi rebaño, la oveja más pequeña salta el regacho dos pies']. Entonces, Marzo le respondió diciendo a Abril: “Ai Apiril, Apiril!, bazeuzkat bi egun terdi, ik ekatzak beste bi egun terdi, orroko artzai orri kenduizkagun eun ardi eta bi aari" I'AAy, Abril, Abril! Ya tengo dos días y medio; dame tú otros dos días y medio para que le quitemos a ese pastor de ahí cien ovejas y dos carneros']. A excepción de un carnero, el resto se lo llevó el agua; el pastor cogió el carnero sobre sus espaldas, y con un movimiento brusco, el animal con un cuerno le arrancó un ojo, perdiendo además de su rebaño, un ojo. He podido escuchar relatos parecidos a éste en distintos pueblos. En este relato se refleja el orgullo, el egoísmo del pastor y su infidelidad a la palabra dada, así como el duro castigo que le imponen Marzo y Abril por no cumplir con lo prometido. Una vez transcurridos los días denominados zozomikoteak o artzaitxoaren egunek el tiempo mejoró y adoptó el alegre aspecto de la primavera ${ }^{4}$.

Se deduce de estos párrafos que, en el área vasco-navarra, los días finales de marzo son considerados nefastos para el ganado -fenómeno que tiene una motivación meteorológica y ecológica evidente-, y que ello ha generado dos tipos de reflejo en la mentalidad y la vida comunitarias: uno puramente supersticioso, que pone énfasis sobre lo nefasto de los días zozomikoteak o artzaitxoaren; otro, más estructurado y complejo, que eleva a la categoría de culto católico y conmemoración anual las creencias sobre la divinidad asociada y al mismo tiempo protectora contra tales días nefastos. Ello demuestra que estratos diferentes de las creencias que nos ocupan pueden convivir y superponerse en los mismos espacio y tiempo; y también vivir cerca pero disociados, como revelan los siguientes refranes ejemplificadores exclusivamente de la vertiente supersticiosa:

"Martxuen kunkunak jotzea, idiari larrua kentzea".

'Marzo azotando, al buey despellejando'.

"Martxo kaldartx, ez ardi ez artantxo".

"Marzo caluroso, ni oveja ni cordero'

+ Garmendia Larrañaga, "Amabirjina Martxoko en Aizarnazabal", Fiestas de invierno (Donostia-San Sebastián: Diputación Foral de Gipuzkoa, 1993), pp. 70-71. Agradezco la traducción del diálogo en euskera a losu Reparaz.

Mikel AZURMENDI, Nombrar. embrujar: para una bistoria del sometimiento de la cultura oral en el País lasco (Zarautz: Alberdania, 1993), p. 66. 
El campesino vasco cree que sólo con la llegada de abril y de la primavera, la supervivencia del ganado queda garantizada:

"Martxoak buztanaz, apirilak bularraz".

'Marzo con el rabo, abril con la teta'.

-San Benito primadera, ganaduak larrerar.

'San Benito primavera, ganados a pastar't .

A medio camino entre la pura superstición ganadera y el culto católico formal a Nuestra Señora de Marzo se encuentran otros refranes que sitúan en la festividad de esta Virgen el punto de inflexión simbólico entre la meteorología invernal y la primaveral, entre la precariedad de los meses fríos y el resurgir de la naturaleza y de los ciclos ganadero y agricola:

"Ama Berjina Martxoko, neguari eman diok ostikon.

'Madre Virgen de Marzo, has dado coz al invierno'.

"Andra Maria Martiko, artean udäa tatiko, andik aurrera betiko".

'Nuestra Señora de Marzo, hasta entonces el verano indeciso, en adelante para siempre'.

"Andre Dena Maria Martxoko, behiak mendian halako".

'El día del Nuestra Señora de Marzo, las vacas han de alimentarse en la montaǹa'.

“Andre Maria Martxoko, beiak larrean asekom.

"Nuestra Señora de Marzo, las vacas se hartarán de pastizal'".

"Andramari Martxoko, behiak mendian alhako".

'N.' Sra. de Marzo, las vacas pastarán en el monte' .

Pese a la confianza con que el campesino vasco esperaba la llegada de la fiesta de la Virgen que traía simbólicamente el final del invierno, lo común y lógico era que el mal tiempo todavía rivalizase y alterase el resurgir primaveral durante los días zozomikoteak o artzaitxoaren de finales de marzo y comienzos de abril, y muchas veces también, durante al menos un mes más, hasta las fechas también simbólicas de la Pascua y, sobre todo, del día de San Marcos (25 de abril):

6 AZURMENDI, Nombrar p. 66.

- AZKUE, Euskalerriaren III, pp. 29-30.

8 AZURMENDi, Nombrar p. 66. En la tradición folclórica castellana el mes de marzo también era generalmente considerado nefasto para la agricultura y la ganadería, aunque ocasionalmente se situaba en él el despuntar de la primavera. Véase por ejemplo Francisco Rodríguez MARín, Los refranes del almanaque (Sevilla: Imp. de Francisco de P. Díaz, 1896), p. 60: -En Marzo, sale la yerba aunque le den con un mazo; y en abril, en cada regacil»; y p. 61: ‘En Marzo, florecen todos los campos. 
*Amabirinina Martxoko lora, larrabehia mendian gora.

Nagusiak: San Markos noiz da?

-Artiaz goiz da - larrabehia eskarmentatuakn.

"N." Sra. de Marzo en flor, la vaca de pasto al monte. Dijo el amo: - ¿Cuándo es San Marcos? Y la vaca escarmentada respondió: -Es pronto todavía'.

"Behiak: -Ama Martxoko, behia larrean haseko.

Idiak: - Nik apirilari beldur, ez ote duen zizerkora eta lur".

'Dijo, la vaca: -N. ${ }^{a}$ Sra. de Marzo, la vaca a saciarse en el prado-. Pero respondió el buey: - Yo temería a abril, no sea que granice y hiele'.

"San Markos egun arteraino, txintxarria bete lasto".

'Hasta S. Marcos manténgase el cencerro lleno de paja - avisó el buey-' (es decir, que no se saliera a pastar y no sonase, por tanto, el cencerro).

"Andramari Martxoko. ni mendirat opoko- antzuak.

- Ni Erramuren beldurtxo- zaharrak erantzun".

-N." Sra. de Marzo, subiré a los pastos- dijo la necia. Y la vieja: -Yo temería hasta Pascua".

"Larrabeiak San Markoserarte txintxarria bete lasto gordetzeko esan zuen".

'La vaca silvestre dijo que hasta San Marcos se le guardara paja que cupiera en un cencerro'"

"Andra Maria Martxoko, ni mendirat opokon.

-Nuestra Señora de Marzo, yo al monte sobre talones-. (Esto lo dijo la oveja estéril, y la oveja vieja le contestó: - Ni erramuren bildurxko- - - Yo tengo algún miedo del dia de Ramos)' 11.

"Aptrilia, biribila, zerria urdandegian otzak ila".

'Abril redondo, el cerdo muerto de frío en la pocilga' ${ }^{2}$.

El periodo del resurgir primaveral cuyo inicio marcaba simbólicamente la fiesta de la Virgen de Marzo, se afianza ya definitivamente el día de san Marcos, justo un mes después, cuando suelen producirse los últimos temporales peligrosos:

"San Markosek kazkabarra agoan du".

'San Marcos tiene granizo en la boca' (es decir. cerca de su día caerá granizo) ${ }^{13}$.

\footnotetext{
? AZlRMENDI, Nombrar, p. 68.

11 AZKL'E, Euskalerriaren, I, p. 313.

"AZkLE, Euskalerriaren, III, p. 30.

12 AZKLE, Euskalerriaren, III, pP. 151-152.

1; AzklE, Euskalerriaren, III, p. 35.
} 
Lo cual no impide que, por San Marcos, la época de la siembra quede definitivamente abierta:

"San Marcos-astea, artoa ereiteko astea".

'Semana de San Marcos, semana de sembrar el maíz' ${ }^{14}$.

En una tradición distinta a la vasca, la asturiana, era ya la llegada de mayo la que garantizaba la salvación para el ganado. Lo expresa muy bien el refrán asturiano

"A Mayo, pol rau",

que explicaba así su editor: "Que el ganado, en llegando a este mes, ya puede considerarse salvado, por tener comida en el campo" ${ }^{15}$.

A propósito del gradual, conflictivo y peligroso tránsito del invierno a la primavera que el pueblo sitúa preferentemente entre los últimos días de marzo y los primeros de abril, y su reflejo en las creencias, supersticiones y religiosidad vascas, ha escrito Mikel Azurmendi estas significativas palabras:

Bajo el refrán y la pequeña narración semi-épica que, de manera abundante, trazan el antagonismo entre marzo y abril, se suele significar que, tras el prolongado invierno, el espacio vital se halla en peligro $[\ldots]$ Hay ciertamente una escenificación de agónica disputa a vida o muerte entre ambos meses; no se olvide que el invierno ha solido ser muy duro para el caserío pues, una vez acabado el stock de provisiones, los mugidos y balidos del ganado hambriento solía acallarlos demasiado a menudo el campesino con carros de espinosa árgoma, ramaje casi seco y hasta duro cañamaje que, mal que bien, rescataba de entre las nieves [...] De ahí que ver acabarse el invierno sea la condición de que continúe el espacio doméstico: marzo y abril disputaban por su égida - vienen a decir decenas de pequeñas historietas de ganaderos- y cuando ya parecía terminar marzo, éste le pidió dos días más, tan sólo dos, para acabar con los animales y hombres que habían osado desafiarle saliendo ya a pastar a campo abierto. Abril se los concedió. Arreció entonces de tal modo marzo, que fue matando uno a uno los rebaños. Un toro logró, sin embargo, guarecerse bajo una encina y allí se mantuvo con los hierbajos que lograba extraer de la nieve con sus pezuñas delanteras. En otra versión, un pastor logró salvar únicamente al carnero del rebaño y se lo echó al hombro, pero cuéntase que en un inopinado movimiento, el animal con el cuerno le sacó un ojo a su amo. De ahí las lacónicas expresiones a manera de prudente sentencia que sirven para no caer en triunfalismos: "Apiril, biribil. 'Abril redondo', que significa: “ ¿Cuidado con abril!. [...] En otras versiones, abril no le concede esos dos días demandados por marzo y en ellas aparece el

14 AZKUE, Euskalerriaren, III, p. 35.

15 Luciano CASTAÑón, Refranero asturiano (Oviedo: CSIC, 1962), p. 34. 
campesino proclamándose dueño y señor. Así, "Apiril, biribil, ekatzik egun bi. A! Martxo kakatso, har zak esker gaizto. Nere ardirik kaxkarrenak egiten dizkik zazpi salto!n 'Abril, redondo, jlárgame dos días más! Pero el otro responde: Ay, Marzo de mierda, a ti mi más sentido desagradecimiento. Hasta la peor de mis ovejas está dando ya saltos'. Porque lo que efectivamente se vehicula tras ese combate épico entre dos meteorologías antagónicas es una imagen significante con la que dar sentidr, a una dura experiencia: la cultura doméstica se simboliza como enclave difícil donde se asiste a su victoria sobre la naturaleza, victoria basada esencialmente en el ejercicio de la inteligencia prudente. Esa especie de zona de nadie que media entre el 25 de marzo (Andramari Martxoko) y el 25 de abril (San Markos) constituye el ritual de la soberanía del sujeto doméstico; ahí se experimenta él mismo como dueño y señor de los animales y de su propio recinto ${ }^{16}$.

3. LA FESTIVIDAd CATÓlICA DE LA ANUNCIACIÓN DE LA VIRGEN SE CELEBRA EL 25 DF MARZO

Más adelante vamos a conocer una serie de fábulas hispánicas, europeas, africanas y asiáticas relacionadas con las anteriores y que siguen teniendo por protagonistas a un pastor o a una vieja que dialogan con una deidad controladora del ciclo meteorológico acerca del sacrificio prometido, no cumplido y castigado que tan familiar nos resultará ya. Pero antes conviene observar que la fecha del 25 de marzo de estos cultos marianos caracterizados, pese a su revestimiento cristiano, por una fuerte carga ideológica supersticiosa, mágica y legendaria, coincide con la fiesta católica de la Anunciación en que el Ángel comunicó a María su próxima maternidad. Sólo el Fvangelio de San Lucas (I:26-38) relata este suceso, y sólo a partir del siglo $V$ se tienen noticias fidedignas de que la Iglesia celebrase el 25 de marzo la fiesta de la Anunciación, pese a que autoridades muy posteriores, como Benedicto XIV, pretendiesen que la fiesta era de institución apostólica $^{{ }^{-}}$. Es evidente que, al menos en España, existe un vínculo entre la fiesta de la Anunciación y de las heterodoxas Vírgenes de Marzo que coinciden cada día 25 de ese mes. Sobre la celebración de estos cultos en el Pirineo se ha dicho, por ejemplo, que "lo crítico del momento agrícola, la salida de la Semana Santa y las reminiscencias paganas, crearían el máximo romero anual, comenzando por la Virgen de Marzo - Anunciación-,

16 Azlrmend, Nombrar; pp. 65-67. Datos adicionales sobre la rivalidad de los meses de marzo (mes de hombres) y abril (mes de mujeres) se podrán encontrar en Azkue, Euskalerriaren 1, p. 08.

1- Véase en el monumental Dictionnaire de Théologie Catbolique, 3a ed. (Paris: Libraire Letouzey et Ané, 1920- ), s.t: Annonciation. una descripción detallada de las circunstancias teológicas e históricas de esta fiesta. 
incrementándose en los comienzos de las pascuas primera y segunda, y llegando al techo para las fiestas de la Trinidad y de San Juan" ${ }^{18}$.

Es bien sabido que lo más importante del calendario celebrativo cristiano se fue construyendo, especialmente entre los siglos IV y vil, sobre la base de festividades paganas anteriores, cuyo culto pretendió - sin demasiado éxito- erradicar, y luego parcialmente asimilar, la emergente autoridad religioso-política eclesial. Hoy existen datos y bibliografía más que suficientes para que no se pueda dudar de que la fiesta de la Natividad de Cristo se instituyó el 25 de diciembre exactamente sobre la pagana del nacimiento del dios Sol, y que la de su muerte se hizo coincidir a propósito - para "borrarla" - con la de la muerte de Atis; o que las fiestas de carnaval, mayo, San Juan, etc. se superpusieron con gran precisión temporal al ciclo festivo pagano precedente. No tengo noticias de ningún estudio sobre los orígenes y antecedentes de la fiesta de la Anunciación de la Virgen que la iglesia católica conmemora cada 25 de marzo, coincidiendo con el equinocio de primavera. Pero el hecho de que el momento de la Anunciación presente justamente un diálogo entre un ser humano - la Virgen - y uno sobrenatural —el ángel-, como sucede en las antiquísimas y extendidas fábulas de El pastor y marzo que estamos conociendo, la coincidencia exacta en las fechas, y el explícito vínculo "Anunciación = Vírgenes de Marzo" que acerca la festividad eclesial a la órbita y a la función de las leyendas y supersticiones agropastoriles que estamos conociendo, parecen elementos que podrían apoyar la hipótesis - aquí sólo propuesta - de que la institución por la Iglesia de la fiesta de la Anunciación el 25 de marzo respondiese a la intención de superponerse y asimilar, de dar una dimensión de "conmemoración" histórico-religiosa, a un mito o un rito mágico-pagano anterior, extendido por buena parte de Europa, Asia y África como lo está hoy, del mismo tipo que los que nos están ocupando.

\section{El CUENTO DE "El PASTOR Y MARZO"}

Ciertamente, la fábula sobre los días que el expirante mes de marzo pide prestados a abril, reproducida o aludida por Garmendia Larranaga y por Azurmendi, es conocida no sólo en la geografía tradicional vasconavarra ${ }^{19}$, sino también en muchas otras áreas de nuestra Península y de

18 Enrique SATLÉ OLIVÁN, Religiosidad popular y romerías en el Pirineo (Huesca: Diputación, 1991), p. 150.

19 Véase la referencia a otras versiones vascas publicadas por AZKUE y por Barandiarán en Julio Camarena, Cuentos tradicionales de León, 2 vols., (Madrid-León: 
los tres continentes que bordean el Mediterráneo. Podemos empezar a comprobarlo a partir del siguiente cuento, recogido por mí a una mujer del pueblo de Zagra (Granada):

$$
\begin{aligned}
& \text { Cuando marzo revuelve el rabo, } \\
& \text { no quea oveja sin pellejo, } \\
& \text { ni pastor enzamorrao. }
\end{aligned}
$$

Eso era que [un pastor] le dijo [a] marzo, le dijo que si le daba un mes bueno, pues que le regalaría un borrego. Se lo dijo [el pastor]. Y dice:

-iBueno!

$Y$ ya, pues dice:

- ¡Yo no le doy el borrego! ¡Ya que quean pocos días, qué le voy a dar!

Bueno, y luego y vino [marzo] y dice:

-iQue el trato [es] que me tienes que dar el borrego!

Se lo dijo San Pedro. Dice [el pastor]:

—Digo, ya, pa lo que queda!

Dice [marzo):

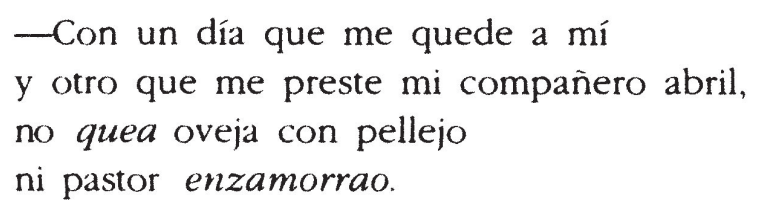

Y vino una tormenta $m u$ grande, y tan solo se metió un borriquillo debajo de una cardera, y vino un granizo y le partió el rabo. Y toas las ovejas se murieron, del mes que le dio marzo y otro día que le prestó abril ${ }^{20}$.

Como se puede fácilmente comprobar, el argumento del cuento granadino es esencialmente coincidente con la historia del pastor y la Virgen que los lugareños sitúan en el origen del culto de la Pellejera castellana, y con las tradiciones y cultos en torno a la rivalidad de marzo y abril y a Nuestra Señora de Marzo del área vasco-navarra. El hecho de que la celebración de todas estas vírgenes tenga lugar cada 25 de marzo, cuando justamente faltan muy pocos días para que termine tal mes, y detalles como el del refugio debajo de un caldero y la congelación del rabo del animal que aparece en la leyenda castellana y en el cuento granadino, y que es también rastreable en una de las versiones vascas aludidas por Azurmendi (la del toro que se guareció abajo una encina y allí se mantuvo con los hierbajos*), revelan un parentesco estrecho e inconfundible. Otras

Seminario Menéndez Pidal-Universidad Complutense de Madrid-Diputación Provincial de León, 1991), núms. 67 y 68 (véase vol. I, pp. 106-107 y 397).

20 La informante Carmen Cervera, nacida en Zagra hace unos ochenta años (ignora su edad exacta), fue entrevistada en Vallecas (Madrid) el 30 de marzo de 1994, en una encuesta realizada junto con Ángel Berenguer Amador. 
versiones del cuento son más breves y presentan menos puntos de coincidencia. Una mujer del pueblo de Ganuza (Navarra), me contó esta versión:

Le decía un pastor, le decía a marzo, que ya no le tenía miedo. Y le dice [marzo]:

-Ocho días que me quedan,

y otros ocho que me acompane mi hermano abril, te dejaré sin ovejas en el cuadril ${ }^{21}$.

Algunas versiones tienen por protagonista al mes de febrero, y el papel de marzo queda relegado al de prestamista de los pocos días que se necesitan para consumar la hecatombe ganadera. La misma mujer de Ganuza que me contó la anterior versión, sabía también esta:

Estaba un pastor, ¿verdad?, que tenía los cordericos pequeños. Como febrerico estaba bastante bueno, le decía:

$$
\begin{aligned}
& \text {-Febrerico corto, } \\
& \text { ya no te tengo miedo, } \\
& \text { porque mis cordericos están } \\
& \text { con un dedico de cuerno. }
\end{aligned}
$$

Y le dice febrero:

$$
\text { -iCalla, calla! }
$$

Ocho días que me quedan

y otros ocho que me acompana

mi hermano marzo,

te haré ir con los cencerricos

debajo el brazo.

Empezó a llover y a nevar y se murieron todos. ¡Claro!

Otras versiones en que los protagonistas son febrero y marzo son las tres siguientes, también recogidas por mí en los pueblos de Espinareda de Ancares (León), Lorca y Estella (Navarra):

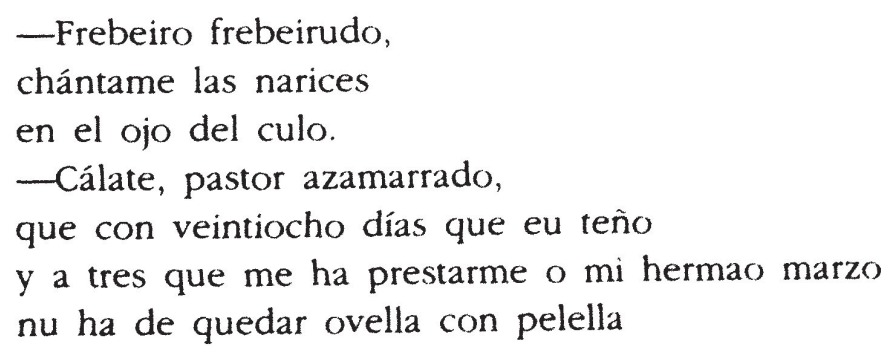

21 La informante María Socorro Vidán, nacida en Ganuza en 1932, fue entrevistada el 26 de agosto de 1995, en una encuesta realizada junto con Alfredo Asiain y Mariola Roa. 
nin can con rabo

nin pastorino azamarrado ${ }^{22}$.

Cuando ya iba bueno el mes, pues estaba el pastor un poco atrás si le ofrecía, si no le ofrecía. Y cuando ya estaban ya sobre el veintiseis o así, pues una mañana, bien buena mañana, dice:

- ¡Febrerico! ¡Ya has visto el cordero!

¿Entiendes? Ya, como quedaba poco tiempo, dice:

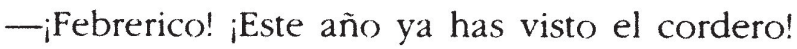

$\mathrm{Y}$ dice que oyó una voz que le dice:

- Con dos días que me quedan

y dos de ini hermano marzo,

te quedarás con los cencerros

debajo el brazo 23 .

Esto lo decía un pastor:

-Adios, febrerico el corto, que eres el más corto del año.

$Y$ salta febrerico:

- Con dos días que me deje mi amigo marzo, te jodo todo el rebaño ${ }^{24}$.

Finalmente, un texto muy evolucionado que conserva sólo alguno de los tópicos de nuestra fábula es el siguiente refrán recogido por mí de la tradición de Galende (Zamora):

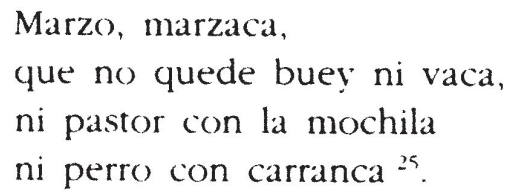

Nuestra fabulilla está bien documentada en la tradición hispánica desde al menos el siglo xir. Francisco de Espinosa, en su Refranero compuesto entre 1527 y 1547 , fue el primero en hacerse eco de él:

$\because$ La informante Rosa Abella, de 68 años, fue entrevistada en Espinareda de Ancares (León) el dia 16 de julio de 1993.

$\therefore$ El informante Javier Ros, nacido en 1943, fue entrevistado en Lorca el día 22 de agosto de 1995, en una encuesta realizada con Mariola Roa.

2. El informante Emilio Salsamendi, de 75 años, nacido en Estella, fue entrevistado alli el día 20 de agosto de 1995.

25 La informante Consuelo Sanz, nacida en 1911, fue entrevistada en Zamora el 3 de octubre de 1995. 
Quando março buelbe de rrabo, ni dexa ni pasto[r] ençamarrado (ni carnero ençençerrado) ${ }^{26}$.

Otra versión quedó documentada, muy poco después, en el Libro de refranes de Pere Vallés (1549):

Alla vayas Febrero corto co[n] tus dias venyte [sic] y ocho: que lleuaste lo d'ogaño: alla queda Março mi hermano que quando buelue de rabo: ni dexa pastor ençamarrado: ni carnero encençerrado ${ }^{2^{-}}$.

Gonzalo Correas, en su Vocabulario de refranes fechado en 1627, anotó igualmente dos versiones:

Si marzo buelbe de rrabo, ni kedará ovexa, ni pastor enzamarrado.

Si marzo buelbe de rrabo, no dexa kordero enalmagrado, ni pastor enzamarrado, ni karnero enzenzerrado 28 .

Finalmente, en el inédito Manuscrito 10.925 de la Biblioteca Nacional de Madrid, anotado posiblemente ya entrado el siglo xvili, figuran estas dos versiones:

En marzo pega el sol como mazo.

y si marzo buelbe el rabo.

ni queda ganado,

ni pastor enzamarrado.

Allá bayas Febrero loco,

con tus días veynte, y ocho

mal has burlado a mi ganado:

acá queda tu hermano Marzo, que si buelbe el rabo, ni deja pastor enzamarrado, ni carnero encerrado ${ }^{29}$.

El cuento-refrán de El pastor y marzo ha sido ampliamente documentado en la tradición folclórica moderna de todo el mundo hispánico ${ }^{30}$. Se halla

26 Francisco DE ESPINOSA, Refranero (1527-1547), ed. E. D. O'Kane (Madrid: Real Academia Española [Anejo XVIII del Boletin de la Real Academia Españolal, 1968), p. 153.

2- VAllés, Libro de refranes (Zaragoza: en Casa de Juana Milian..., 1549), f. 7v.

28 CORREAS, Vocabulario de refranes y frases proverbiales, ed. L. Combet (Burdeos: Université, 1967), p. 289.

29 Ms. B.N.M. 10.925 [Papeles varios del s. XVIII], ff. $90 \mathrm{v}$ y $105 \mathrm{v}$.

30 Véase Ralph S. BogGS, Index of Spanish Folktales [FF Communications 90] (Helsinki: Academia Scientiarum Fennica, 1930), n." 2415 . Julio Camarena, en Cuentos tradicionales de León núms. 67 y 68 (véase vol. I, pp. 106-107 y 397) publicaba dos 
además documentado en las tradiciones de otros países europeos, como Francia - donde Fréderic Mistral lo incluyó en su novela Mireille-, Suiza, Italia, Gran Bretaña o Malta; y también del mundo árabe africano y asiático, como Marruecos, Palestina, Siria o Líbano ${ }^{31}$. En la mayoría de las

versiones leonesas y hacía referencia a docena y media de versiones folclóricas publicadas en castellano, asturiano, catalán, euskera y portugués. A ellas se pueden añadir las siguientes: Carlos PLENTE ÚBEDA, Meteorologia popular o refranero meteorológico de la Peninsula Ibérica (Madrid: Sucesores de Cuesta, 1896), pp. 191-203; RodríGuez Marin, Los refranes, pp. 45-47 y 70-72; A. THOMAZ PIREs, "Dictados agrícolas", Revista Lusitana XIV (1911), pp. 169-183, pp. 170-171; Jesús TABOADA, "Folklore astronómico y meteorológico de la comarca de Monterrey", RDTP V (1949), pp. 110-137, pp. 134 y 137; "Refranero de los meses", Hoja Folklórica 2. "etapa, (Salamanca, 20-2-1956), p. [1]; José luis PÉrfz de CASTRO, "Dialogismos en el refranero asturiano", RDTP XIX (1963), pp. 116-138, p. 137; Luciano CASTAÑón, "Apuntes folklóricos sobre la vaca en Asturias", RIDTP XXVIII (1972), p. 312; Manuel TABOADA CID, "Algunos aspectos de la vida material y espiritual de A Mezquitan, Boletín Auriense VIII (1978), pp. 107-166, pp. 153-155; Juan Muciarza, Tradiciones, mitos y leyendas en el País Vasco, 2 vols. (Bilbao: [edición del autor], 1987), II, p. 269; Simón Guadalajara SOlera, Lo pastoril en la cultura extremeña (Cáceres: Institución Cultural "El Brocense", 1984), pp. 51-52; Manuel VIEGAS Giferreiro) y António Machado Glerreiro, Literatura popular do distrito de Beja (Beja: Direçào-Geral da Educaçào de Adultos, 1986), p. 65; José Ramón FERnández G(IN7.Ál.F., "Dichos y refranes del valle de Ancares (León)", RDTP XLII (1985), pp. 191217. p. 213; El tiempo. Meteorología y cronologia populares, dir. J. F. Blanco (Salamanca: Diputación, 1987), pp. 125-127; Cristóbal BARRIOS RODRÍGlez y Ruperto BarRIos 1) Mincit'E7. Crónica de La Guancha a tratés de su refranero (Santa Cruz de Tenerife: Excmo. Cabildo Insular, 1988), p. 284; Isabel BOTAS SAN MARTín. La maragatería (Vigo: Cardeñoso, 199()), p. 73; Santiago CASTElAO DiÑEIRO, Refranero berciano (León: Lancia, 1991), pp. 22 y 82; Ramón SORDO SOTRES, Historias, costumbres. palabras e ideas. Entre los rios Sella y' Nansa (Gijón: El Jogueru, 1992), p. 76: Virgilio FERnÁndez ACEBO, Manuel Oria Martinez-Conde y J. Ignacio López García, Dichos y refranes de uso común 'n los lalles del alto Pas y del Miera (Vega de Pas: Asociación Científico Cultural de Estudios Pasiegos, 1992), p. 68; P[adr]" CLNHA BRITO, "Etnografia minhota", Revista Lusitana XV, nueva serie (1992), pp. 290-311, p. 304; e Isabel BOTAS SAN MARTín, "Los refranes agricolas en el refranero tradicional maragaton, Revista de Folklore 156 (1993), pp. 18.3-189, pp. 184 y $18^{-}$.

31 Véase al respecto P[aul] M[EYER], "Les jours d'Emprunt, Romania III (1874), pp. 294-29-: la reseña de Stanislao PRATO a J. B. FrÉDÉRIC ORTOLI, Les contes populaires de lîle de Corse, (Paris: Maisonneuve, 1883) [Les littératures populaires de toutes les nations t. XVT] Romania XIII (1884), pp. 168-176, p. 170; René BASSET, aLes jours d'emprunt chez les arabes., Rev'ue des Traditions Populaires V (1890), pp. 151-153; Eugène Rolland, Faune populaire de la France, 13 vols. (reed. Paris: Maisonneuve et Larose, 1967), vol. V. pp. 83-84; Rodriguez MaRín, Los refranes pp. 70-72; y, sobre todo, J. Cassar-Plllicino, "Some parallels between Maltese and Arabic Folklore", Acta Ethnografica Academiae Scientiarum Hungaricae XXXIV/1-4 (1986-1988), pp. 143-175, pp. $156-158$. 
versiones extrahispánicas, la protagonista que dialoga con marzo -alguna vez también con febrero o incluso con enero- suele ser una vieja -infrecuente en textos peninsulares-, en vez de un pastor. La suma de indicios resultantes de su multicultural arraigo folclórico avala que el arquetipo de la fábula debe ser antiquísimo, y puede seguramente remontar a la más vieja herencia común de los pueblos indoeuropeos. Se conocen, por añadidura, más datos que apuntan en la misma dirección.

\section{El CiClO ESTACIONAL, LA ECOLOGÍA INVERNAL Y LAS SUPERSTICIONES GANADERAS}

Nada hay más repetitivo, inexorable y "ritualizado" que el ciclo estacional y sus efectos - primero- en la ecología y en el hábitat humano, y - -segundo- en la vida social y espiritual del hombre. Toda la actividad económica y cultural de las sociedades más tradicionales se ajustaba al ritmo que marcaba la meteorología y el devenir de las estaciones. Y el calendario de efemérides - fastas y nefastas-, como marcador y regulador básico de los ciclos productivo y espiritual de la sociedad, funcionaba como una especie de "calco" cultural del ciclo ecológico y estacional al que se superponía. A las creencias y fábulas en torno al final del mes de marzo que estamos conociendo se les puede presumir un trasfondo muy primitivo por varias razones: en primer lugar, por su arraigada difusión folclórica en lenguas y culturas distintas de tres continentes; además, por sus atávicos elementos mítico-animistas que se manifiestan en el diálogo y la invectiva personal del hombre a una fuerza natural destructiva antropomorfizada - el mes de marzo, a veces alternante o combinado con enero, febrero o abril- ${ }^{32}$; y, sobre todo, por su carácter de "ritualización" cultural de algo que tiene que ver con la experiencia directa del hombre con su entorno natural y con el sometimiento de su actividad a los condicionantes meteorológicos y estacionales. Una estudiosa portuguesa ha señalado que:

32 Los mitos de antropomorfización de las potencias naturales (el sol, la tierra, el agua, el fuego, las tormentas) se asocian a los estadios más primitivos de desarrollo cultural de cualquier sociedad. A veces sobreviven, fuertemente desemantizados y ritualizados, en las culturas modernas. Sobre un mito de personalización e invectiva a los genios de las tormentas que se ha mantenido en la tradición moderna de toda Europa, puede verse mi artículo "La pizarra latina de Carrio (siglo vili) y la cuestión de orígenes de la literatura tradicional románica y european, Actas del VI Congreso de la Asociación Hispánica de Literatura Medieval (Alcalá de Henares, septiembre 1995), en prensa. 
fevereiro é o mes mais frio do ano. A friage [friagem] atinge, sobretudo, os mais fracos. O elevado índice de mortalidade verificado nessa altura levou à criação do adágio seguinte: "Fevereiro, / leva a velha e o cordeiro" ${ }^{33}$.

Y Mikel Azurmendi, en un párrafo reproducido anteriormente, también señalaba que

el invierno ha solido ser muy duro para el caserío pues, una vez acabado el stock de provisiones, los mugidos y balidos del ganado hambriento solía acallarlos demasiado a menudo el campesino con carros de espinosa árgoma, ramaje casi seco y hasta duro cañamaje que, mal que bien, rescataba de entre las nieves ${ }^{34}$.

En el pueblo de Ganuza (Navarra), me hablaron de la desgracia que sólo dos años antes de recoger mis informes, en 1993, había acontecido a un pastor que se había atrevido a esquilar sus ovejas en el mes de marzo, en vez de en el mucho más adecuado de abril, lo cual motivó la muerte por congelación del ganado:

"En abril, la abeja y la oveja dejan la pelleja". Aquí, en abril, al pastor, allí en el monte se le quedaron tiesas, ¿eh? Se quedaron congeladitas, tiesas, por haber esquilao tan pronto. $\mathrm{Y}$ eso pasó hace dos años. $\mathrm{Y}$ las esquiló en marzo. Y me acuerdo que le estábamos tomando el pelo:

-iA ver si te vas a quedar sin calzoncillos!

Y cambió el tiempo y hacía muchísimo frío:

-iA ti también te tenían que haber dejao así en colitatis, como todas las ovejas! $Y$ dice:

- Pues mira, que se me han muerto siete. Tiesas las he encontrao esta mañana.

Y que había dejao tres sin esquilar, porque estaban muy flacas, y que dijo:

-Éstas no las voy a esquilar para ver si aguantan si viene algún cambio de tiempo. -Dice: - Son las únicas que me han aguantao.

¿Ves cómo los antiguos sabían ${ }^{35}$ ?

La elevada mortalidad que entre el ganado producía el invierno, sobre todo cuando llegaba a su fin y los animales se encontraban más debilitados por el largo encierro, el frío y la deficitaria alimentación a base exclusivamente de forraje seco, es un hecho empírica y estadísticamente indiscutible. Acentuaba el problema el nacimiento, poco antes, de las desvalidas

3. Maria Teresa CAETANO, "Literatura oral na região de Colares", Etnografia da regiào saloia: a terra e os homens (Sintra: Instituto de Sintra, 1993), pp. 169-184, p. 170.

it AZurmendi, Nombrar, p. 65.

35 La informante María Socorro Vidán, nacida en Ganuza en 1932, fue entrevistada el 26 de agosto de 1995, en una encuesta realizada junto con Alfredo Asiain y Mariola Roa. 
crías, pues «en el sistema tradicional, las ovejas paren una vez al año un cordero entre los meses de diciembre a febrero, que se desteta aproximadamente al mes" ${ }^{36}$. Una vinculación explícita entre las duras condiciones meteorológicas del mes de marzo y la supervivencia del ganado la encontramos en una anécdota referida al casi legendario pastor navarro Zacarra, muerto en 1850:

Zacarra sentenció sin moverse del lecho, queriendo reflejar lo caprichoso del tiempo, y las pocas confianzas que le infundía el mes de marzo:

- iTolín! Febrero es loco y marzo no poco. Para los viejos y los animales es un mes muy pijotero. Razón tenía aquel salacenco al decir que cuando marzo mueve el rabo, no deja pastor enzamarrado, ni carnero encencerrado ${ }^{3 .}$.

El carácter extremo y adverso para la ganadería del mes de marzo ha dejado su huella no sólo en nuestra fábula, sino también en otras muestras del saber popular que reflejan el mismo fenómeno con otras palabras. Así, en la misma tradición portuguesa, hay un refrán que vuelve a referirse a los últimos días de marzo ("rabo de Março") y a los primeros de abril ("Cabeça de Abril") como período crítico para la supervivencia invernal del ganado:

"Rabo de Março, cabeça de Abril, nunca ao mundo havia de vir; perde a burra o rincho e ó porco o quincho" ${ }^{38}$.

La tradición catalana puede ser muy ilustradora al respecto. Alguna vez, enero es considerado un mes nefasto para el ganado:

"Tronades de gener maten l'ovella i el corder".

"Quan trona pel gener, per al bestiar no va bé».

"Ventades de gener maten l'ovella i el pastor també.

“El gener treu el grix del corder, el febrer el despulla i el març se'n porta la culpan.

*Ah gener, generot, que m'has mortes ses ovelles i s'esquellot" ${ }^{39}$.

36 Fermín DE LEIZAOLA, "La distribución del tiempo entre los pastores de ovejas latxas", CEEN XXIII/57 (1991), pp. 49-53, p. 50.

37 Javier SAGÜES, "Zacarra, el cabrero de Gallipienzo", Cuadernos de Etnología y Etnografia de Navarra XXIV/59 (1992), pp. 25-37, p. 34.

38 Manuel VIEgAS GuERREIRO, Pitões das Júnias: esboço de monografia etnográfica (2. ${ }^{2}$ ed. Lisboa: Serviço Nacional de Parques, Reservas e Património Paisagistico, 1982),

p. 264. Rincho significa 'relincho'.

39 Joan AmADEs, Folklore de Catalunya: Cançoner (reed. Barcelona: Selecta, 1982), p. 961. Despulla significa 'desnuda' y esquellot 'esquila'. 
Pero, en la tradición catalana, febrero es considerado un mes mucho más destructivo que enero para los animales:

"Fred de febrer, pitjor que el de gener".

„El febrer no deixa ovella ni corder".

"Mata més xais el febrer que el carnisser".

"Maleit febrer, que t'emportes l'ovella i el corder" ${ }^{40}$.

"El febrer, no deix ovella ni corder".

"El febrer, tira ovelles al fosser" ${ }^{41}$.

Marzo es, sin embargo, para el campesino catalán, el causante de mayor mortalidad entre el ganado:

"Març, marçot, mata l'ovella i l'ovellot, a la vella vora del foc i a la jove si li trob".

"Març, cagars, de l'ovella en faràs pedaç" 42.

"Març, marcell, no m'has mort cap vaca ni vedell, truja ni porcella, cabra ni cabrit; malhaja, ara que ets finit".

"No sóc l'abril gentil, sinó el març marçot, que em revenjo de tot, i mato les ovelles i els ovellots i, si et descuides, a tu i tot a la vora del focm.

"Març, março, mata la vella a la vora del foc, i la jove, si pot".

"Si el març marceja, no et fïs d'ell; mata l'ovella i castiga l'anyell".

"Març, marçàs, de l'ovella en faràs pedaç".

"La vaca, el març la fa i el març la mata".

"Eugues i vaques, pel març les més flaques".

"Passat el març marcell, salvats la vaca i el vedell».

"Marş, marçot, mata l'ovella i l'ovellot, i el pastor, si pot".

"Març aborrascat, ni ovelles ni corders ha deixat" ${ }^{+3}$.

Un interesante proverbio en dialecto italiano de Calitri vuelve a poner de relieve el poder destructivo del mes de marzo sobre el ganado:

"Quann' marz' s' lu ss'bbota lu cappiegghj, nguorp' a la vacca trema lu v'tiegghj".

4h AMADES, Folklore: Cançoner pp. 965-966. Xais significa 'corderos'.

4 Esteve Busquets I MOLAS, Els animals segons el poble (Barcelona: Millà, 1987), p. 194 .

42 BUSQUETS 1 MOLAS, Els animals, p. 194.

43 AMADES, Folklore: Cançoner, pp. 970-971. Vedell significa ternero'; truja y porcella 'cerda'; anyell 'cordero'; y eugues 'yeguas'. 
Un paralelo suyo en italiano dice

"Quando marzo mette il cappello sulle 23, nel corpo della mucca trema il vitello" ${ }^{* 4}$.

Al ser traducido 'Cuando marzo se pone el sombrero sobre el día veintitrés, en [o junto a] el cuerpo de la vaca tiembla el ternero', el proverbio nos permite valorar el arraigo internacional de la superstición. Y, también, apreciar la fecha del 23 de marzo, próxima a la del 25 en que se festeja a las Vírgenes ganaderas castellanas y vasco-navarras, y localizada en los últimos días del mes en que la tradición sitúa preferentemente sus días más críticos y peligrosos.

\section{LOS díAs finales de MARzo, NEFAStos PARA El GANAdO}

Esta creencia concuerda muy sugerentemente con el hecho, ya apuntado por Garmendia Larrañaga en un texto reproducido al comienzo de este estudio, de que también en la tradición vasca los últimos días de marzo son nefastos:

Los zozomikote son días tristes y oscuros. En las localidades guipuzcoanas, los días denominados zozomikoteak o artzaitxoaren egunek se refieren a los dos o tres últimos días de marzo y los dos o tres primeros días de abril [...] una vez transcurridos los días denominados zozomikoteak o artzaitxoaren egunek el tiempo mejoró y adoptó el alegre aspecto de la primavera ${ }^{45}$.

Pues bien, en Francia, tal creencia estuvo igualmente muy extendida. Eugène Rolland ya puso de relieve, relacionando esta superstición con las leyendas de El pastor (o la vieja) y marzo, que "hay siete días del año - cuatro de marzo y tres de abril- que nuestros padres temían mucho y que bautizaron como los vaqueros (lous vochès) [...] Estos días nefastos se llaman en la región del Midi jours vaqueirious, vaccarious, vacairials, bacairials, baqueirouns, cavaliés, cabaliés, según las provinciasn ${ }^{46}$. El origen ganadero de esta superstición no precisa de mayor comentario, vistos los nombres, derivados o paralelos de vaca y caballo, que se le asocian. Lo curioso es que además, en otras zonas europeas, que llegan hasta Escocia, existen supersticiones de tipo parecido, que se manifiestan en hechos como el de que alas gentes supersticiosas se abstienen de pedir

49 A Raffaele Salvante, Proverbi Calitrani (Calitri: Edizioni "Il Calitrano", 1986), ก. ${ }^{\circ} 171$.

45 Garmendia larrañaga, Amabirjina Martxoko, pp. 70-71.

46 Traduzco de Rolland, Faune V, pp. 83-84. 
prestado o prestar en alguno de estos días; y si alguien quiere pedir algo prestado en estos días, se supone que tiene la intención de emplear el objeto prestado para hacer algún sortilegio contra el prestatarion ${ }^{47}$. Eco evidente del temor supersticioso que inspiraba la fábula de los días prestados por abril a marzo. Además, "en la tradición palestina, también se encuentra un período de tres "días prestados" en febrero, seguidos de otros cuatro días de marzo durante los cuales la lluvia cae abundantemente, las tormentas arrecian y el frío se hace sentirn. Tal período es allí conocido como mustaqrêdât ${ }^{48}$.

\section{LA PROMESA INCUMPLIDA}

El rigor meteorológico y la elevación de la tasa de mortalidad ganadera que se hacen sentir en el mes de marzo, y la "reacción" cultural que ello provoca en el sistema de creencias, mitos y ritos de algunas sociedades agropastoriles, constituyen el entramado básico del arquetipo que estamos analizando. A este armazón elemental se ha superpuesto un motivo folclórico que, por estar presente en distintas ramas de nuestra fábula, es merecedor también de atención: el del castigo por el sacrificio prometido pero no satisfecho, bien conocido en la tradición folclórica y literaria desde muy antiguo ${ }^{49}$. Cabe recordar, por ejemplo, que este motivo se ha asociado ocasionalmente a cultos marianos parecidos a los que nos han ocupado hasta ahora, como prueban diversas Cantigas de Alfonso X el Sabio que llevan títulos tan significativos como éstos: Esta é como Santa Maria fez fazer aos babous que crian a seda duas toucas, porque a dona que os guardava lle prometera hũa e non lla dera; Esta é como Santa Maria

† Traduzco de P[aul] M[EYER], "Les jours d'emprunt, p. 296.

* Traduzco de Cassar-Pullicino, "Some parallels", p. 157.

*4 Véase al respecto Stith THOMPSON, Motif-Index of Folk Literature: a Classification of Narrative Elements in Folktales. Ballads, Myths, Fables, Mediaeval Romances, Exempla, Fabliaux, Jest-Books and Local Legends, ed. rev. y aum., 6 vols. (Bloomington \& Indianapolis-Copenhague, Indiana University-Rosenkilde \& Bagger: 1955-1958), núms. K231.3, .Refusal to make sacrifice after need is past. In distress a person promises a sacrifice to a god (saint) but disregards the promise when the danger passes. ['Negativa a cumplir el sacrificio después de que la necesidad haya pasado. En un apuro, una persona promete hacer un sacrificio a un dios (o santo), pero incumple la promesa cuando el peligro pasa']; M205, :Breaking of bargains or promises. ['Ruptura de pactos o promesas']; Q223.3, .Neglect to sacrifice punished. ['Negativa a hacer un sacrificio castigada']. Todos estos motivos aparecen en cuentos tradicionales de la India, antigua Grecia y de las tradiciones semíticas y europeas, lo que avala su extraordinaria antigüedad. 
levou o boi do aldeão de Segovia que ll'avia prometudo e non llo queria dar, Esta é como Santa Maria fez queimar a lãa aos mercadores que offereran algo a sua omage, e llo tomaran depois ${ }^{50}$.

El motivo permanece sólidamente asociado a cultos marianos plenamente vigentes. Una mujer de Espinareda de Ancares (León), me informó así sobre el culto a la Virgen de Trascastro, de la que era muy devota:

Un señor estaba ciego y le han dicho que la Virgen de Trascastro, que está en la Fornela, es muy milagrosa. Dice: -Ofrécete ir a la Virgen de Trascastro, que es muy milagrosa, que te vuelva la vista-. Y se ofreció. Y dice: - Ofrécele algo, porque...- Le ofreció la pareja de bueyes que tenía en casa. Y fue a Trascastro y cuando llegó adonde se empieza a ver el santuario le volvió la vista. Y veía tan perfectamente. Bueno, vino para casa y le ha dicho a la mujer: - iEh! ¿Y ahora la vamos a dar la pareja de bueyes? ¡Ahora la vista ya la tengo! - El caso que no se la quisieron dar. Y se volvió a quedar ciego. Eso dicen que es cierto, que no es mentira ninguna ${ }^{51}$.

\section{SACRIFICIOS A MARI. SACRIfICIOS A MARTE}

La importancia del motivo del sacrificio prometido pero no satisfecho a la divinidad puede ser crucial para la comprensión de los antecedentes lejanos de las fábulas que nos están ocupando, por cuanto tal motivo se halla presente en estratos de raíz muy arcaica de nuestra tradición cultural. Si volvemos a atender a la órbita vasca, las siguientes líneas de José Miguel de Barandiarán nos traerán sugerencias inmediatas:

Quien hace anualmente un obsequio a Mari no verá caer pedrisco sobre su cosecha (Cortézubi). El mejor obsequio que se le podría hacer era sin duda llevar a su antro un carnero. En muchas leyendas aparece este animal como especie predilecta de Mari [...] Este numen condena la mentira, el robo, el orgullo y la jactancia, el incumplimiento de la palabra empeñada y el faltar al respeto debido a las personas y a la asistencia mutua. Los delincuentes son castigados con la privación o pérdida de lo que ha sido objeto de la mentira, del robo, del orgullo, etc. [...] Castiga también apoderándose de algo que pertenece a los culpables. $\mathrm{Si}$ éstos son pastores, Mari les quita algún carnero ${ }^{52}$.

50 Alfonso X el SABIO, Cantigas de Santa Maria, 3 vols., ed. W. Mettmann (Madrid: Castalia, 1986-1989), núms. 18, 31 y 35. Véase además, sobre más motivos similares en la cuentística hispánica medieval, John ESTEN KELLER, Motif-Index of Medieval Spanish Exempla (Knoxville: The University of Tennesee Press, 1949), $\mathrm{n}^{2} \mathrm{~K} 231.3$.

51 La informante Rosa Abella, de 68 años, fue entrevistada en Espinareda de Ancares (León) el día 16 de julio de 1993.

52 José M.a DE Barandiarán, Mitología vasca (reed. San Sebastián: Txertoa, 1990), pp. 115, 119 y 120. Sobre la diosa Mari, véase también Julio Caro BarojA, Sobre la 
Ciertamente, este culto sacrificial a Mari, tradicional en el País Vasco, equipara -sólo en este punto concreto- a la divinidad vasca con el mes y con las Vírgenes de marzo a quienes se aplacaba o pedía el favor por medio de ofrendas similares. Y presenta puntos de coincidencia muy llamativos, como el del castigo de "la mentira, el robo, el orgullo y la jactancia, el incumplimiento de la palabra empeñada" que Mari practicaba, igual que sucedía con la Virgen de la Pellejera o el mes de marzo en muchas versiones de la fábula de El pastor (o la vieja) y marzo. El hecho de que ese castigo de la jactancia y de la promesa incumplida por el pastor se concretase además en la pérdida del ganado vuelve a ser un elemento significativamente en común con el escarmiento que sufrían los campesinos que osaban desairar a la Virgen o a marzo.

Aunque el paralelismo credencial y funcional "Vírgenes de Marzo $=$ mes de marzo = Mari" sea evidente al trasluz de la documentación analizada, hay motivos para creer que el vínculo genético sólo es directo, estrecho e indiscutible entre los dos primeros elementos, "Vírgenes de Marzo" y "mes de marzo", mientras que las coincidencias con los sacrificios vascos a Mari revelan un parentesco indudable, pero en grado más lejano y seguramente puntual y ocasional, que posiblemente tendría que explicarse más cabalmente en conexión con otros ritos sacrificiales dedicados a divinidades de diferentes religiones arcaicas. Aunque autores como Mircea Eliade se han extendido ampliamente sobre el papel de los sacrificios humanos y ganaderos en muchas culturas como garantes de las cosechas ${ }^{53}$, el culto antiguo con el que más claramente entroncan los que hemos analizado quizás sea el de Mamurius veturius, trasunto de Marte, que se celebraba en fecha tan significativa como el 14 de marzo en la antigua Roma. Sobre él escribió James George Frazer estas palabras que también nos traen interesantes sugerencias:

Ahora estamos en condiciones de fijarnos en el uso de la víctima expiatoria en la antigüedad clásica. Todos los años, el día 14 de marzo, era llevado en procesión por las calles de Roma un hombre cubierto de pieles al que pegaban con cayados blancos y largos para terminar echándole de la ciudad. Le llama-

religión antigua y el calendario del pueblo vasco (San Sebastián: Txertoa, 1984), pp. 6172; y "Las lamias y otros mitos", Mitos vascos y mitos sobre los vascos (San Sebastián: Txertoa, 1985) pp. 7-53.

4 Véase Mircea ElIADE, Tratado de historia de las religiones, trad. T. Segovia (reed. México D.F.: Era, 1991), pp. 308-314, especialmente párrafos tan significativos como el de la p. 314, sobre costumbres acon las cuales se cierra el ciclo agrario, [y sobre] los sacrificios que tienen lugar cuando se lleva la cosecha a las granjas, etc. [Por ejemplo,] Los finlandeses, al empezar la siega, sacrifican el primer cordero nacido en el año..." 
ban Mamurius Veturius, o sea ael viejo Marte», y como la ceremonia tenía lugar un día antes de la primera luna llena del antiguo ano romano (que comenzaba el primero de marzo), el hombre vestido de pieles representaba el Marte del año anterior que echaban al principio del Año Nuevo, pues Marte no era en su origen un dios de la guerra, sino de la vegetación; era a Marte a quien el labrador romano oraba por la prosperidad de sus mieses y sus viñas, sus árboles frutales y sus talleres; era a Marte a quien el colegio sacerdotal de los hermanos Arvales, cuya ocupación era sacrificar para el crecimiento de las cosechas, dirigía sus peticiones casi exclusivamente; era a Marte, como ya vimos, a quien se sacrificaba un caballo en el mes de octubre para asegurar una abundante recolección. Además, era a Marte, bajo su título de "Marte de los Bosques" (Mars siluanus), a quien los agricultores ofrecían sacrificios por la prosperidad de sus ganados. Ya hemos visto también que a los ganados se les supone corrientemente estar bajo el patronato especial de los dioses arbóreos. Aún más, la consagración del vernal mes de marzo a Marte creemos que le señala como la deidad de la vegetación germinante ${ }^{54}$.

El nombre latino del mes de marzo era Martius, es decir, 'de Marte' o 'consagrado a Marte' ${ }^{55}$. Y en tal mes, aparte de la de Mamurius veturius, había otras dos fiestas dedicadas a este dios. Además, cada cinco años se sacrificaban, para asegurar la fecundidad del campo y del ganado, un toro, un jabalí y un carnero en el Campo de Marte ${ }^{56}$, eco seguro de "los viejos tiempos en que seres humanos, especialmente prisioneros de guerra, eran sacrificados [a Marte] para aplacarle" ${ }^{57}$. La mecánica y hasta las oraciones que acompañaban a estos sacrificios "marciales" han quedado minuciosa-

${ }^{4}$ FRAZER, La rama dorada: magia y religión ledición reducida], ed. E. y T. I. Campuzano (reed. México: Fondo de Cultura Económica, 1981), p. 651. Otra fiesta hispana en la que diversos autores han visto reminiscencias de las antiguas celebraciones romanas de Mamurius veturius es la mascarada conocida como El cascamorras que tiene lugar en las localidades de Guadix, Baza y otros pueblos granadinos. Véase al respecto Salud ANDrés APARICIO y Ana GRANados VAlverde, Antropología de una fiesta granadina: "El cascamorras" (Granada: Universidad, 1990), especialmente pp. 60-66, y la bibliografía que cita.

55 Véase al respecto Gertrude JOBES, Dictionary of Mytbology, Folklore and Symbols, 2 vols. (Nueva York: Scarecrow, 1962), s.v. Mars.

56 Mircea Eliade y Ioan P. Couliano, Diccionario de las religiones, trad. I. Arias (Barcelona: Paidos, 1992), p. 244. También en la Hispania prerromana y romana existieron cultos a Marte y a divinidades predecesoras suyas en que los sacrificios de ganado tenían una importancia fundamental. Véase al respecto G. LOPEZ MONTEAgudo, "Avance sobre el culto a Marte indígena en la Península Ibérica", Estudios sobre la Antigüedad en homenaje al profesor Santiago Montero Díaz [Anejos II de Gerión] (Madrid: Universidad Complutense, 1989), pp. 327-332, y la bibliografía que cita.

57 Traduzco de JoBEs, Dictionary s.v. Mars. 
mente documentados ${ }^{58}$, y han merecido el siguiente comentario, crucial para el entendimiento del arquetipo cultural que estamos analizando, de Eli Edward Burriss:

El dios Marte a quien se dirigían estas fórmulas es, naturalmente, un dios completamente desarrollado, identificado en las ceremonias institucionales como el dios de la guerra; pero los ritos y oraciones se remontan a un período más primitivo, cuando el hombre no hacía distinción entre él mismo y los elementos y fuerzas que le amenazaban en su pugna con la naturaleza. Los agricultores primitivos probablemente se dirigían no a un dios, sino al mal, a la escasez, etc. como personajes reales, y siendo al parecer incapaces de concebir una de estas fuerzas emanando de algo distinto de sí mismo, fueron gradualmente dotando de personalidad a tales elementos ${ }^{59}$.

\section{REPETICIÓN Y REgENERACIÓN DEL MITO. De NUEVO LA CUESTIÓN DE LO RITUALIZADO Y LO CONMEMORADO}

Resulta bastante probable que uno de esos "ritos primitivos" en que el hombre antropomorfizaba "los elementos y fuerzas" naturales pueda ser el representado por nuestro cuento del pastor (o la vieja) que habla, promete, engana y es contestado y castigado por el mes de marzo. Igual que resulta evidente que en las fábulas y creencias que hemos conocido en torno a El pastor (o la vieja) y marzo, El pastor y la Virgen de la Pellejera, Nuestra Señora de Marzo, Mari o Marte, aparecen elementos estructurales comunes que se explican por contigüidad o influencia mayor o menor entre las diversas ramas, o por remontarse, en última instancia, a ese arquetipo credencial primitivo al que se refería Burriss, en que el hombre se enfrentaba directamente a las fuerzas de la naturaleza "personalizadas".

De todo ello se infiere que el estadio de la fábula más arcaico de todos los que conocemos es seguramente el de El pastor (o la vieja) y marzo, conclusión que se ve además reforzada por su amplísimo arraigo multilingüístico y multicultural en tierras de tres continentes. Una difusión así sólo es explicable a partir de un antiquísimo arquetipo indoeuropeo que habría ido incorporando, en cada tiempo, en cada espacio, en cada tradición y en cada lengua, rasgos particulares aglutinados en torno a los motivos estructurales básicos. Sabemos que el nombre de Marte «está relacionado con el de Mrnati, que en sánscrito designa al que aplasta o

s* Véase, por ejemplo, Eli EdWARd Burriss, Taboo, Magic, Spirits: a Study of Primitive Elements in Roman Religion (reed. Westport, Connecticut: Greenwood Press, 1972), pp. 167-171.

‘9 Traduzco de Burriss, Taboo p. 170. 
destruye $^{60}$. Es un indicio más del trasfondo arcaico que puede esconderse tras el nombre y los atributos del Marte=Marzo romano. $Y$ otro aval que apunta hacia un arquetipo prelatino de nuestras fábulas y creencias, pese a que lo que conocemos - seguramente de forma no exhaustiva- de su difusión folclórica actual en áreas fundamentalmente mediterráneas y pertenecientes al antiguo Imperio romano podría apoyar la fácil impresión de que el cuento y los ritos de El pastor (o la vieja) y marzo podrían ser de origen romano.

A modo de conclusión, no resulta aventurado afirmar que, en un estadio muy arcaico de desarrollo de las sociedades indoeuropeas, la influencia de los ciclos meteorológicos y estacionales sobre los agropastoriles y culturales determinó que se practicaran ciertos ritos de sacrificio y propiciación a las fuerzas naturales, progresivamente mitificadas, que se identificaban con el final del invierno y, en el mundo mediterráneo más concretamente, con el final del mes de marzo. En este marco debió de nacer la fábula de un hombre o mujer que transgredía las prescripciones sacrificiales ganaderas al mes de marzo o a la divinidad que se le asociase, y que era por ello castigado con la muerte a causa del frío de su rebaño. En época romana, estas creencias debieron relacionarse con las que encarnaban Mamurius veturius y su trasunto Marte, dioses primigeniamente de la agricultura y la ganadería destinatarios de cultos sacrificiales de tipo similar y estrechamente ligados al mes de marzo. También en época muy antigua, pero en el dominio vasco, estas creencias debieron aproximarse a las que había en torno a la diosa Mari, de perfil también marcadamente agropastoril. Aparte de todo lo averiguado sobre la identificación -incluso por motivación mítica y onomástica- de marzo y Marte, sobre sus cultos agrícolas y ganaderos y sus ritos sacrificiales, conviene recordar que en la religión romana, "[Ares = Marte] es también el Castigador y el Vengador de todas las ofensas, y particularmente de la violación de los juramentos; [y] también es honrado a veces como el dios del juramento" ${ }^{61}$. Marte reunía, por tanto, todos los requisitos de equiparación con el implacable Marzo de mitos y ritos anteriores - y también posteriores- que castigaba la promesa incumplida del pastor. En mucha mayor medida, desde luego, que la vasca Mari, también exigente de sacrificios ganaderos y matadora de las reses no entregadas, que puede considerarse otra rama subsidiaria, de rasgos muy específicos y originales, del tronco arcaico de las deidades naturales protectoras del ganado.

\footnotetext{
60 Traduzco de JOBES, Dictionary s.v. Mars.

61 Jean Chevalier y Alain GheERBrant, Diccionario de los simbolos, trad. M. Silvar y A. Rodríguez (reed. Barcelona: Herder, 1991), p. 138.
} 
De los estadios más antiguos de estas creencias es más lo que sabemos por deducciones de "estratigrafía", mitología y literatura comparadas que por certeza documental de todos los procesos y cambios desarrollados. Sin embargo, en las fases evolutivas posteriores el terreno se hace más firme, yá que se avanza algún paso desde el mundo de lo mítico a lo histórico, de lo ritual a lo conmemorado. Las Vírgenes de Marzo vasco-navarras y, sobre todo, la Virgen de la Pellejera castellana, que tiene una ermita y un culto católico específicos celebrados cada 25 de marzo, es evidente que son actualizaciones tardías, de época cristiana, de los ritos y mitos folclóricos y paganos preexistentes. Y la fiesta y el culto de la Anunciación - del diálogo de la Virgen y el Ángel- que la Iglesia católica celebra cada 25 de marzo desde los primeros siglos de nuestra era, pudo ser también, hipotéticamente, una fiesta "sustituta", nacida a la sombra del multisecular y difundidísimo diálogo mítico de El pastor (o la vieja) y marzo. Es fácil advertir, en estos últimos estratos cristianizados de nuestro viejísimo arquetipo, una voluntad, que probablemente se expresó también en los cultos romanos a Mamurius veturius y a Marte, de institucionalización del mito, de elevación del ciclo ritualizado "ecología invernal-superstición ganaderamito sacrificial" a la categoría de festividad "conmemorada" en un tiempo y un espacio que el pueblo reivindica como "históricos". El ejemplo más significativo de ello es el de Montemayor de Pililla, donde la época y el solar que fueron supuestos escenarios del encuentro de El pastor $y$ la Virgen de la Pellejera se perciben tan reales e "históricos" que han dado lugar al levantamiento de una ermita y a una conmemoración anual revestida de todos los signos de institucionalización histórico-religiosa. El tránsito de lo mítico a lo histórico, de lo ritualizado a lo conmemorado, puede ser analizado, sobre esta base, como un continuum de extraordinario valor ejemplar sobre las dos coordenadas que enmarcan la evolución socio-cultural de cualquier pueblo: la repetición de ritualizaciones ecológicas, sociales y culturales preexistentes, y la regeneración impulsada por la propia tendencia hacia formas de organización compleja de la sociedad, y por los intereses y la capacidad asimiladora y manipuladora de los grupos socio-religiosos dominantes en cada época y lugar.

Tras un recorrido tan intenso y sugerente por una de las vías mejor transitables y más luminosas, la de la fábula de El pastor y marzo, con que todavía hoy podemos contar para remontarnos y analizar las raíces más profundas de nuestra cultura, sólo queda esperar que otras prospecciones de nuestras tradiciones y de nuestra marginada y amenazada literatura tradicional puedan seguir sumando datos y rasgos al borroso perfil de nuestra identidad cultural; un patrimonio colectivo que, como casi siempre que es estudiado extensa e intensamente, nos lleva a la convicción de que, 
sobre razas, pueblos y lenguas particulares, hubo un antiguo complejo mítico-cultural común que tiene mucho que enseñarnos sobre nosotros y sobre los demás pueblos, sobre nuestro pasado y nuestro presente, y sobre las fuerzas de solidaridad y diferenciación que han actuado entre los unos y los otros, del modo que muy acertadamente resumió Mircea Eliade:

Todo mito, independientemente de su naturaleza. enuncia un acontecimiento que tuvo lugar in illo tempore y constituye por este hecho un precedente ejemplar para todas las acciones y "situaciones" que, más tarde, repetirán ese acontecimiento [...] El mito puede degradarse en leyenda épica, en balada o en novela, o también sobrevivir bajo la forma disminuida de "supersticiones". de costumbres, de nostalgias, etc.; no por ello pierde su estructura ni su alcance [...] Evidentemente, cada nuevo deslizamiento acarrea un "espesamiento" del conflicto y de los personajes dramáticos, un oscurecimiento de la transparencia original, así como la multiplicación de las notas específicas de "color local. Pero los mode-los trasmitidos desde el pasado más lejano no desaparecen, no pierden su poder de reactualización, siguen siendo válidos para la "conciencia moderna" "2.

Jose Manuei. Phidrosa

Diversos cultos católicos espanoles a "Virgenes de Marzon a las que se asocian referentes ganaderos tienen relación con un cuento de El pastor.y marzo arraigado en muchas culturas del Mediterráneo. El estudio de sus fuentes nos lleva a viejos mitos y ritos agropastoriles referidos al dios romano Marte y a la diosa vasca Mari, eslabones de un arquetipo mítico aún más arcaico, de origen probablemente indoeuropeos.

Some Spanish Catholic cults to "Virgins of March" associated with cattle references are related to the folk tale The shepherd and March known in all the Mediterranean area. The study of its sources goes back to ancient agricultural and pastoral myths and rites related to the Roman god Mars and to the Basque goddess Mari, links of a mythical archetype even more archaic, probably of Indoeuropean origins.

62 Eliade, Tratado pp. 385-387. 